\title{
A semiotic approach to Greek Internet Memes during the Covid-19 Pandemic
}

\author{
BY: Thomas Bardakis
}

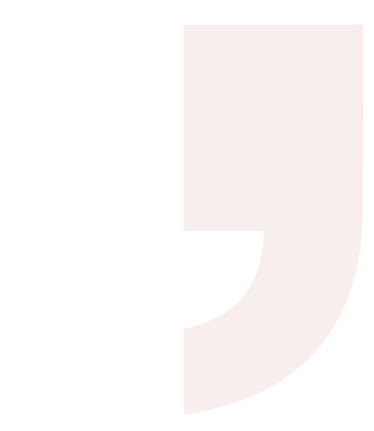

ARTICLE INFO:

Volume: 07

Issue: 01

Summer 2021

ISSN: 2459-2943

DOI: $10.18680 / \mathrm{hss} .2021 .0003$

Pages: 31-43

LiC.: CC BY-NC-ND 4.0

KEYWORDS:

\section{Covid-19}

Quarantine

Humor

Greek memes

\section{ABSTRACT}

ince late 2019, Covid-19 has spread worldwide, and many $\checkmark$ people are obliged to stay at home for public health reasons. Confined to their homes, people worldwide flooded the internet by posting photos and images online with funny captions, attracting an abundance of comments, and proving that humor is a vital need even in the most challenging times. This paper focuses on original Greek internet memes (not those translated into Greek) through selected examples. The study aims to investigate fifteen representations about Covid-19 and the Greek experience of lockdown, focused on quarantine lifestyle issues in Greek social media groups (Facebook, Instagram, Twitter). Memes are explored as humorous and composite visual communication works that highlight how Covid-19 and quarantine have affected our everyday lives.

\section{Introduction}

The first lockdown in Greece began in mid-March 2020. On March 10, all the educational institutions were closed, and on March 13, coffee shops, bars, restaurants, museums, shopping malls, and sports facilities were also shut down. On March 16, all retail stores were closed, and all religious functions were suspended. By the end of May, most of these restrictions were lifted. The second lockdown was imposed on November 7, 2020, reinstating the previous rules until May 2021. During both these periods, the disruption of regular social activities and contacts adversely impacted the economy, our personal lives, and our psychological state. 
This paper deals with the discourse of the Covid-19 pandemic based on humorous internet memes and highlights connotations of their usage in Greek culture. The study contains memes on Facebook, Twitter, and Instagram from March 2020 - May 2021, using a qualitative content analysis method. The data were collected from fifteen selected posts observed by the author about Covid-19, which are publicly accessible. The qualitative approach taken here sees memes in terms of cultural products that are "processes of communication" (Eco 1976: 8) and looks at how observations about lockdowns are constructed. Lockdowns have affected many aspects of everyday life, such as mental-physical-social conditions. The study of humorous memes helps to understand the influence of Covid-19 on Greek society. Many posts published on websites and social media during the pandemic singled out the Greek government's social, economic, and public health practices.

In analyzing the examples of Greek memes created and circulated during the pandemic, the first section will explain what a meme is and what makes memes humorous. Theories about the nature of memes and humor are canvassed. This section concludes with a few brief reflections on the meaning of humor and memes' notion, types, and functions. The second section introduces the mixed methodology of this study, emphasizing its multi-semiotic approach, which directly correlates with the character of the meme as a multimodal semiotic text and image assemblage. This coexistence of two different semiotic systems seems to conduct a semiotic synergy since meaning is created and complemented by different semiotic codes and expressed in a compact semiotic text. The most substantial part of the paper contains the sample memes and interpretations of them. In this part, the main focus is on text-image relationships and how reframing some aspects of social reality into syncretic semiotic texts, such as memes, can lead to humor construction.

\section{The notion of a humorous "meme"}

According to Shifman (2013: 363), "the word meme derives from the Greek mimema, signifying 'something which is imitated.'” A meme is a medium often used to channel humor on the internet and social media (Taecharungroj and Nueangjamnong 2015: 1-2). Shifman (2014) attempts to offer a revised definition of memes to the effect that they seem to be: (a) a group of digital items sharing common characteristics of content, form, and / or stance, which; (b) were created with some awareness of each other, and; (c) were circulated, imitated, and/or transformed via the internet by multiple users (2014: 41). According to Grundlingh (2017), "memes are a common way for individuals to communicate online. Internet users often use memes to reply to each other on social networking sites or other online forums." Also, Grundlingh (2017: 4) believes that "the interpretation of a meme can therefore be seen as a process of signification 
[...] both semiotics and pragmatics assist in contributing to a thorough understanding of how memes are used to communicate." Grundlingh underlines that there are two types of 'joke memes':

1. Memes as jokes: The aim of these memes is simply to be a joke; they have no underlying message. Memes are often used to joke about something or someone. The possible content for these jokes is endless but is typically focused on politicians, politics, religion, and current events or celebrities.

2. Memes as humorous comments / opinions: These memes appear to be jokes, but they comment or provide opinions on grave matters. Humor is sometimes a more accessible vessel to use when one wants to communicate an opinion. Humorous memes that are used to comment on political events, for example, often refer to current events (2017: 17-18).

Aondover (2020: 28) considers "a type of meme that is used on social media like Facebook which consists of image, photographs or in the form of cartoons and macros with a concept or catchphrase of Covid-19." Pauliks (2020: 46) argues that "usually if we hear the term 'meme' we think of amusing images and videos on the internet." As regards the circulation of content on the internet, Pauliks observes that:

The idea that users are infected by viral content and then passively spread it, some argue, is a marketing myth. Instead, they see users as actively involved in the process of deciding what content they will share with other users. The truth no doubt lies between these two arguments. (Pauliks 2020: 46)

Moreover, an internet meme only becomes one when content is copied and changed (Pauliks 2020: 46). Specifically, Pauliks (2020: 47), utilizing Grundlingh's second type of humor, perceives humorous memes as a means that enable users to touch sensitive topics and criticize social aspects with an ironic undertone. Also, he analyzes memes as "collective exchanges," that is, as specific pictorial practices that mirror social reality and need user participation since, without this, they cannot form a group of texts (2020: 49).

\section{Methodology: The Interaction of Text and Image}

As a multi-semiotic text, the meme designates relations between visual and verbal codes; there is a synergistic effect in combining the linguistic semiotic system, graphics, and color codes. To begin with the basics, it is worth mentioning the popular categorization that Barthes provides about the functions of the linguistic message 
concerning the visual message. Barthes' distinction includes two functions: anchorage and relay (Barthes 1977: 38). Barthes starts with the anchorage function, "the most frequent function of the linguistic message" (Barthes 1977: 41) and takes for granted that "all images are polysemous; they imply, underlying their signifiers, the reader able to choose some and ignore others" (Barthes 1977: 39). He adds that the text "helps to identify purely and simply the elements of the scene and the scene itself; it is a matter of a denoted description of the image" (ibid). The second function that Barthes notices is the relay, which is "less common (at least as far as the fixed image is concerned); it can be seen particularly in cartoons and comic strips" (Barthes 1977: 41). In this case, the text and the image develop a complementary relationship, that is, "the words, in the same way as the images, are fragments of a more general syntagm and the unity of the message is realized at a higher level" (ibid.). Finally, Barthes observes that these two functions of the linguistic message can co-exist in the same visual text (ibid).

Consequently, the relationship between different kinds of texts (verbal and visual) can be quite complicated. For Sipe (1998), transmediation is the most accurate method for studying specific connections (text and image) because it allows us to analyze the phenomenological process of the association of words with pictures. Sipe highlights that the synergy of text and illustration completes each other, and the meaning is built from this interaction. Furthermore, Batič and Haramija (2015: 31) support that the interaction between the verbal and the visual codes provides essential information for the reader to understand the message, and inter-iconic links are likely to emerge. Lambert (1986: 139) characterizes inter-iconicity as the fact that one image references another image. For Gamer (2013: 115), the term refers to a general description of visual intertextuality. She defines inter-iconicity as the relationships between images and how they are transformed from one to another (Gamer 2013: 116).

\section{Data collection}

The main question in the present research deals with how the text-image interaction in humorous memes establishes a kind of discourse about Covid-19. The data were collected from social media platforms and grouped according to the two lockdown periods in Greece from March 2020 until May 2021. The approach utilizes discourse analysis in the framework of visual multi-semiotic communication.

For linguists, a discourse has generally been defined as anything "beyond the sentence" (Schiffrin et al. 2015: 1). Van Dijk (2006) attempts to set up a net of relations between ideology and discourse. He considers that "ideologies are expressed and generally reproduced in the social practices of their members, and more particularly acquired, confirmed, changed and perpetuated through discourse." Fairclough's 
(2013: 3) contention is that "ideology is the prime means of manufacturing consent." Ideologies are "representations of aspects of the world which can be shown to contribute to establishing, maintaining and changing social relations of power, domination, and exploitation" (Fairclough 2003: 9). Fairclough sees texts as parts of social events (2003: 21). In addition to this, Fairclough defines social practices as "articulations of different types of social elements which are associated with particular areas of social life" (2003: 25).

The study discusses a selected sample of internet memes used to create humor. There are several alternative ways of reading a meme and many possible ways to understand it. The signs in a meme can be ambiguous. The visual mode of expression, including graphics, drawings, and photographic images, is accompanied by written representations of speech. These representations of speech and visual signs are treated together. Specifically, the idea is to consider "composite, synthetic works (or concepts) that combine image and text," that is imagetexts (Mitchell 1994: 89). The interpretations offered of the selected sample memes consider the interactions of text and image constructions, the codes required to read them, the implied narrative mechanics, the relations of implication, and how these are, in some instances, rendered absurd.

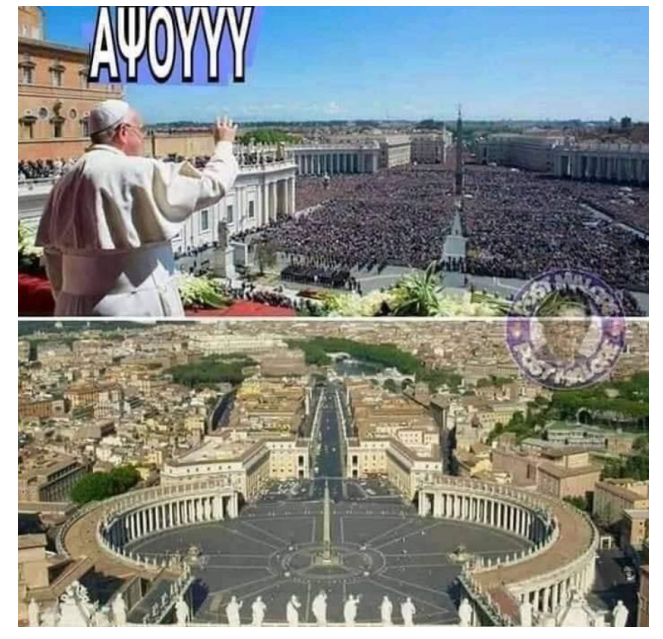

Meme 1 [facebook.com]

\section{A semiotic approach to 15 Greek memes}

The first meme combines two photo frames in one picture, to form a mini-narrative sequence.

In the upper panel, we see the Pope addressing the people assembled in St. Peter's Square, Vatican City, when he suddenly sneezes (indicated by the echomimetic verbal sign

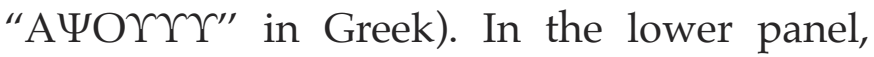
it appears that the people had evacuated the square immediately. This evacuation of the square is implied by narrative mechanics, such as the top-down structure of frames in one image. It is a humorous implication because of the scale (a packed square) and its speed (instantly evacuated from frame to frame) that is realistically impossible. Both scale and speed are vital mechanisms in creating a humorous visual effect. The meme maker added the fake sneeze as a comic element; the consequence is the unrealistic fact that people could leave the square instantly to escape the spray of the Pope's sneeze. This meme shows people's fear about contracting the virus to the degree that they feel the need to bolt from the Pope's presence. 
Meme no. 2 is a cartoon sketch edited with Greek phrases. The overhead title informs us that we are on the 10th day in quarantine to fix the context and determine the point of time. In the bubble,$^{1}$ the woman says: "George, can you give me the hairdryer?" The man, probably her husband, gives her a gun instead. This kind of humor implies that the extended confinement at home with the members of one's family during the quarantine has brought tensions and irritation. In other words, it plays on the adverse psychological impact of the quarantine. It is noteworthy here that this impact is associated with the husband. Specifically, we can observe the cultural stereotype of misogyny expressed in

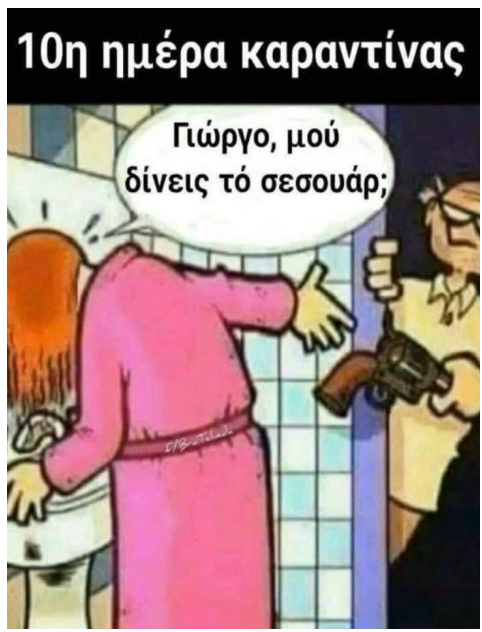

Meme 2 [facebook.com] the man's hostile facial expression, all the while the female figure, pictured with her hair over her face and asking for a hairdryer, seems to fit the cultural stereotype of a narcissistically self-absorbed female. The semiotic equivalence of the gun handle and the grip of a hand-held hair dryer is significant because it represents barely veiled gender violence.

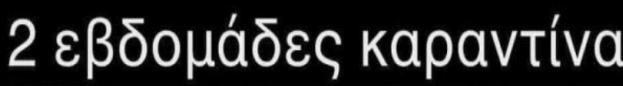

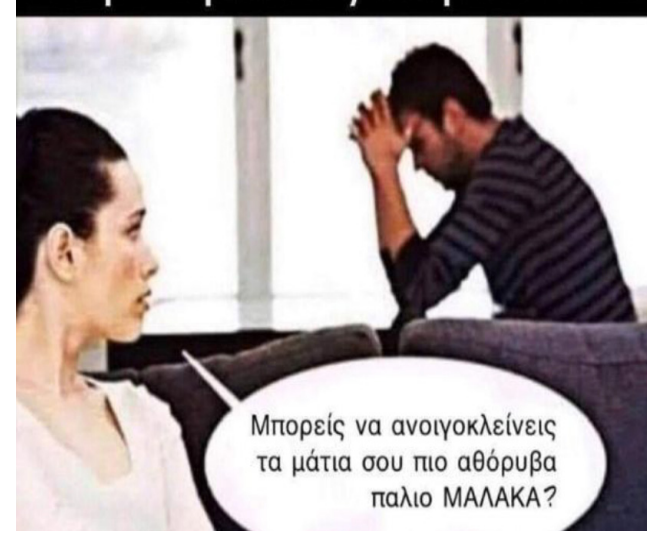

Meme 3 [facebook.com]

Meme 3 doesn't differ substantially from the previous one, apart from the kind of visual sign, here, a photo. The meme-maker depicts the socio-psychological impact of quarantine and lockdown on couples, this time younger couples. The meme has a title, " 2 weeks in quarantine." Moreover, the added speech bubble contains the utterance "Can you blink more quietly, you ASSHOLE?" spoken by the woman, while the man is sitting silent, in a pose suggesting his gloomy mood. The humoristic effect is in the phrase "blink more quietly," highlighting the hypersensitivity towards the behavior of others caused by the condition of confinement.

Meme 4 raises the issue of the restriction of entertainment and social outings during the quarantines. The sketch depicts a couple chatting in a sarcastic mood about their entertainment options. The man says: "I suggest we stay in the kitchen today, and tomorrow if the weather is good, I will take you for a walk in the

\footnotetext{
${ }^{1}$ According to Eco (1994: 155), "the 'bubble' fulfills a specific function." The bubble and the caption in a frame help create "a close fusion between visual information and verbal information."
} 


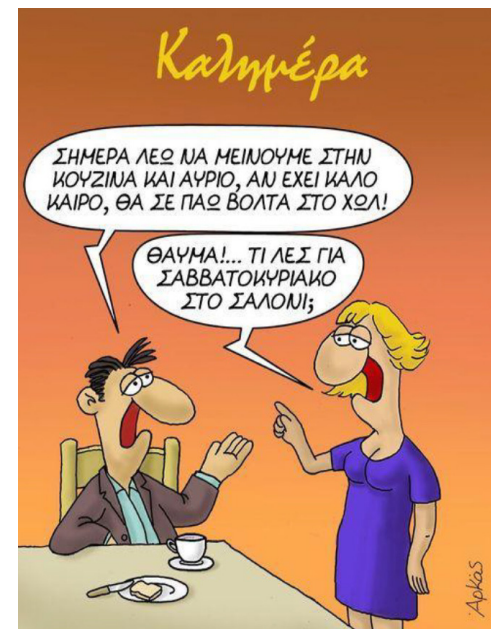

Meme 4 [facebook.com]

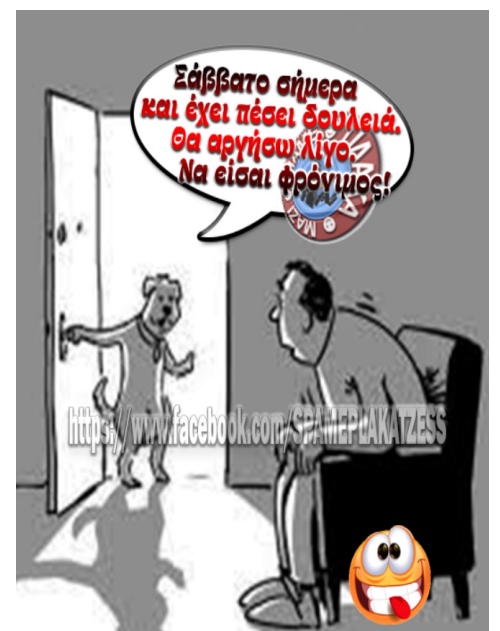

Meme 5 [facebook.com]

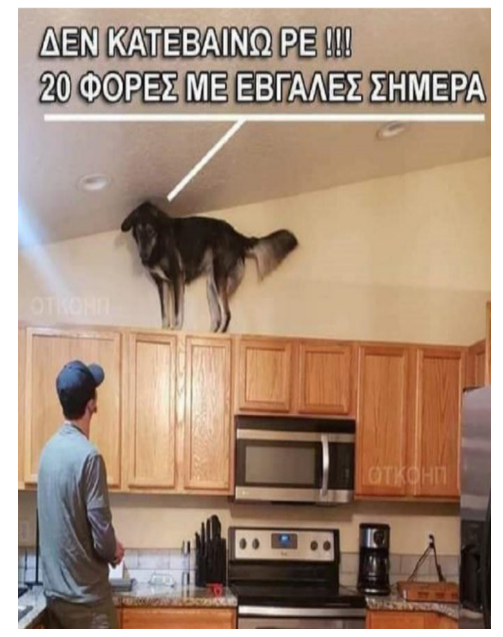

Meme 6 [facebook.com] hall," to which the woman responds: "Great! How about a weekend in the living room?" showing that she follows the conversational mood and enters into the spirit of the imaginative recasting of the domicile as worthy of exploration as if during a vacation.

In Meme 5, we see the humorous treatment of one of the few possibilities for open-air activities allowed during the lockdowns. People were allowed to leave their residence for a series of emergencies but also to walk their pet dogs. In this meme, we can see a man sitting in an armchair alone in a room, looking anxiously at his dog. His dog, represented anthropomorphically as walking on two legs and using the other two as hands, opens the room door and tells him: "Today is Saturday, and there is much work to do. I'll be a bit late. Stay quiet!" The meme creator has effectively reversed the roles of human/pet dog, with the former placed in the position of the home-bound dog, waiting anxiously for his owner to take him for a walk. On the other hand, the dog is placed in the position of a human too busy to spare time for his pet. While the dog is anthropomorphized, the human is animorphized. As his physical pose and general attitude indicate, he is transformed into an obedient, house-broken pet, dependent on its master's whims.

The following meme no. 6 deals with the same human/pet relation topic but with a different focus. The protagonists are again a dog with its owner. In this case, they are in a kitchen, and, once again, an anthropomorphized dog exclaims, "I won't come down!!! You have taken me for a walk 20 times today." The capital letters convey sonic salience to the written text (Nørgaard 2009: 150; Serafini and Clausen 2012: 10) and provide emphasis (Serafini and Clausen, ibid). The frame operates comically by investing in the improbable: a dog refusing to go for a walk and, at the same time, finding refuge high up on the kitchen cupboards, as far away from its owner as possible. 
Meme 7 switches from dog to fish. The caption states the previously mentioned government permission for people to go out for a walk to accompany their pets. The meme showing a man taking a walk with his goldfish satirizes how people used all kinds of seemingly legitimate excuses to get out of their homes.

Meme 8 raises the issue of the poor physical condition that many people suffer due to the constraints of lockdown. This meme is titled "the four stages of quarantine" and contains an inter-iconic, intertextual reference and an inter-semiotic translation of Da Vinci's Mona Lisa. Our conventions in dealing with page design affect the way we must read the meme, "from left to right and from top to bottom, line by line" (Kress and Van Leeuwen 2006: 204). This pattern is due to "a sense of complementarity or continuous movement from left to right" (2006: 180). In addition, "the elements placed

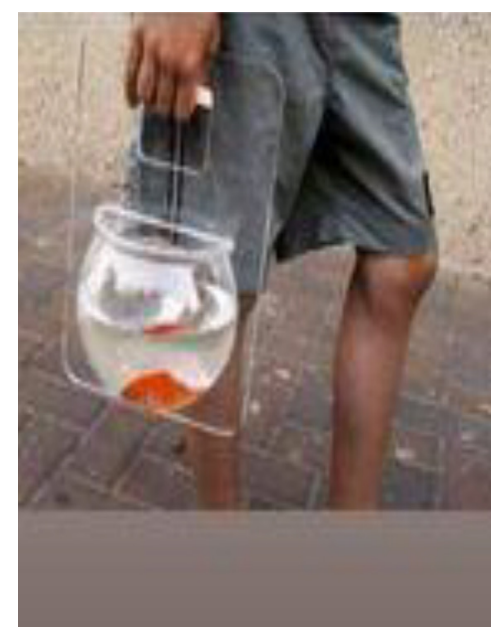

Meme 7 [facebook.com]

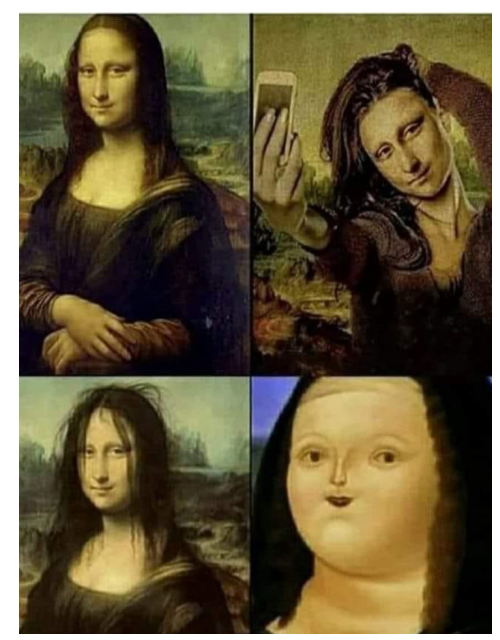

Meme 8 [facebook.com]
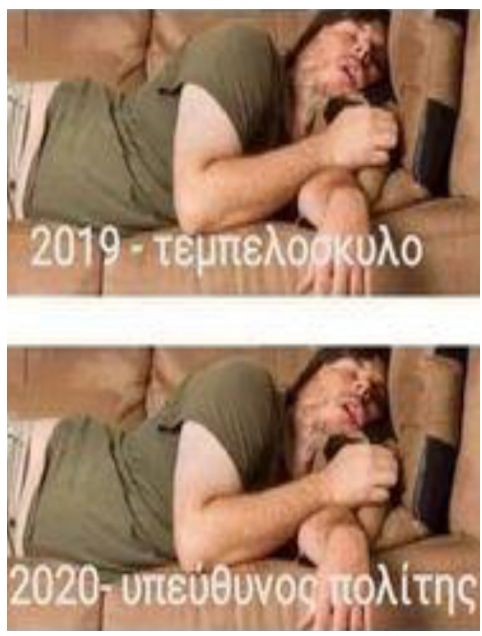

Meme 9 [facebook.com]

on the left are presented as Given, the elements placed on the right as New" (2006: 181). Thus, in the first stage, Mona Lisa appears in her all too familiar, well-groomed, and tranquil pose. In the second stage, we see her playful and carefree, taking selfies, but in the third stage, she appears untidy and messy. The fourth and final stage, Botero's physically exaggerated version of the Mona Lisa, is employed to represent the lockdown's adverse effects on body weight and physical condition. The narrative structure of the meme graphically represents the prolongation of the quarantine as a process of declining mental and physical health. The humor lies in using a cultural icon like the Mona Lisa to allegorize the hardships of the general public. The visual suggestiveness of her transformation makes any additional verbal cues redundant, although Botero's fans are likely to take offense by the satirical use of his picture.

The next humoristic meme is based on the contrast indicated by the two captions: "2019 - lazy dog" vs. "2020 - responsible citizen." The meme's structure high- 
lights image-language relations because the same image acquires entirely different meanings with each caption. The creator suggests that in 2019 someone who used to stay at home all day doing nothing was labeled lazy. In 2020, instead, someone who does the same thing was labeled a responsible citizen, following the government's instructions. The implication is that the lockdown has reversed moral and civil duty hierarchies.

Meme 10 depicts a smiling pilot who has just left his airplane to save himself from the coronavirus. His message on the yellow card says: "I am your pilot. Someone has sneezed. Good luck." The meme is humorous because it seems impossible or excessive for a pilot to leave his plane due to a sneeze. However, the meme represents fearfulness and the lengths to which someone would go not to catch the

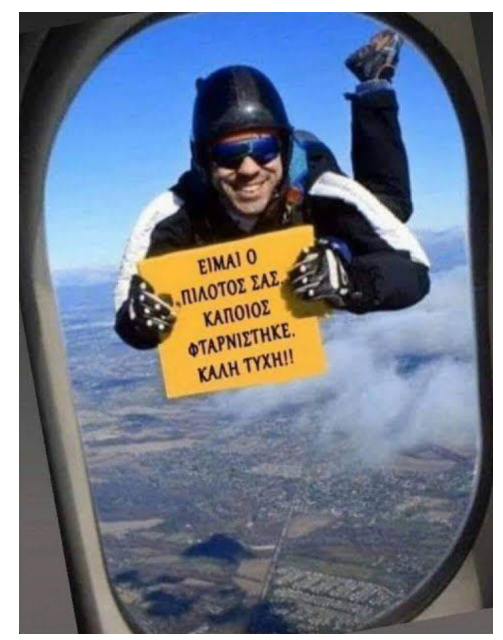

Meme 10 [facebook.com]

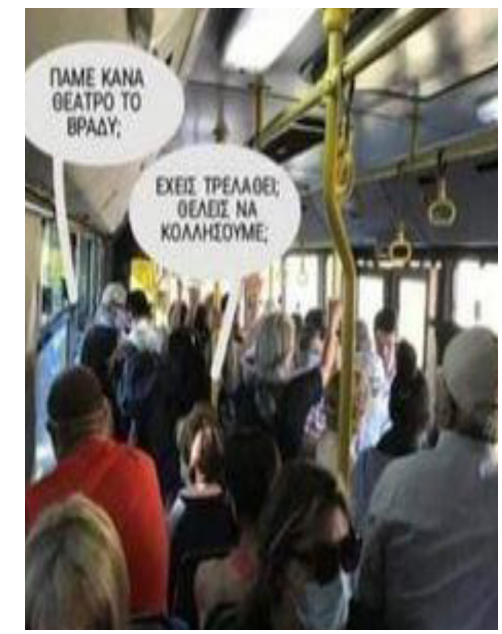

Meme 11 [facebook.com]



Meme 12 [facebook.com]

virus and protect themselves as best they can, under the circumstances. The pilot prefers to take his chances outside the plane than inside a plane filled with the potentially infectious air spray of a sneeze. This meme is linked with the first one as a variation in the reactions due to the sneeze and, thus, it depicts probably the most common way to catch Covid-19 and the urgency of people to escape from the spray range.

Meme 11 was created in mid-June 2020. The strict measures of the first lockdown had relaxed, and people began to return to public spaces. At the time, there was considerable controversy regarding government measures that seemed to risk a new strict lockdown. At the same time, most people felt the need for some degree of freedom of movement. In this meme, we see a crowded bus in a Greek city. Looking at the speech bubbles from left to right, we read: "Would you like to go to the theater tonight?" - "Are you crazy? Do you want to get infected?". The meme lashes out 
against the government's hygiene measures, as it did not invest in public transport and, thus, citizens are crowded together and risk infection. Set in an ironic mode, the meme implies that the real danger for most people is in the full buses and not in the still severely regulated theatre attendance.

Meme no. 12 was released in the second lockdown period, during winter 2020, on an Instagram page. Two people - one of them is from our point of view - play the popular card game Uno. The child, marked as 'Me,' seems happy and carefree, perhaps sure he has a winning hand. Acting as a metaphor for the viewers implies that we are totally naive (childish) to expect the lockdown to be over in a few days. My / Our competitor, Covid-19, seems to have an unbeatable combination of winning cards! A new lockdown appears to be the most likely development. The phrase "The

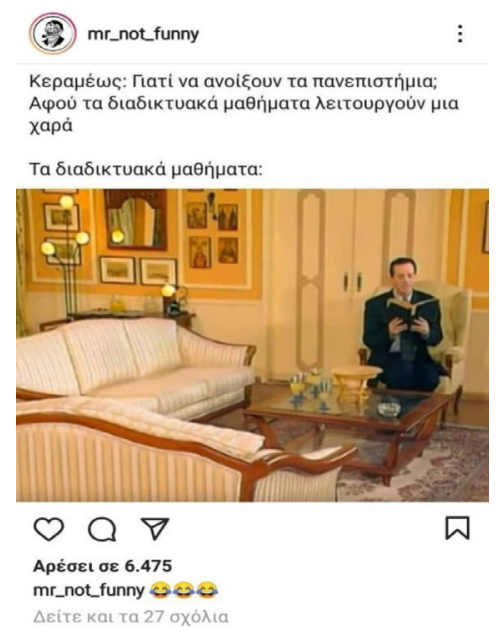

Meme 13 [facebook.com]

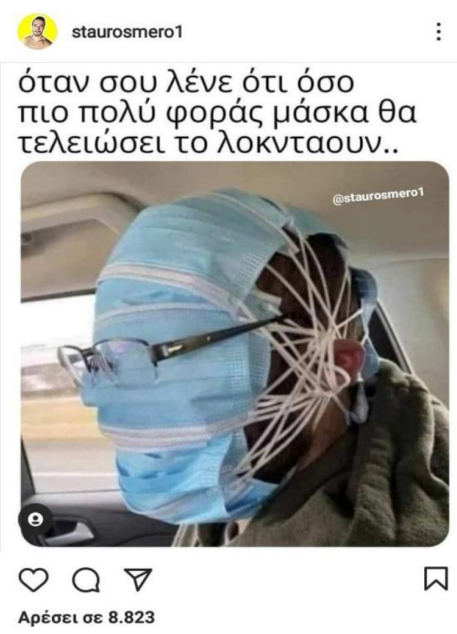

Meme 14 [facebook.com]

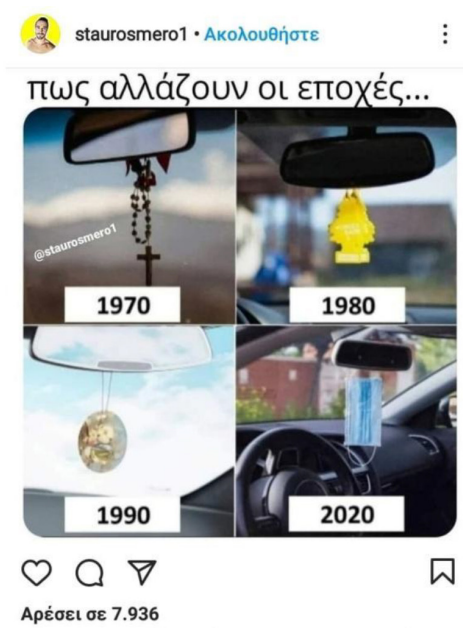

Meme 15 [facebook.com]

next two weeks will be crucial" had by then become a cliché, as it was repeated by the Prime Minister and the Greek mass media from the first month of the lockdown until May 2021. Consequently, it lost all sense of hopeful expectation and solidified ironically in public pandemic discourse.

Another critical issue in the quarantine period was the continuation of educational and training activities through online platforms. This meme represents the students' non-participation due to the nature of the channel through which the educational activity occurs. The caption says: "Kerameus [the Education Minister]: Why open universities? After all, online courses work just fine" - "Online courses." The image is taken from the popular television comedy series Konstantinou kai Elenis to anchor the viewer's gaze and be recognizable through intertextuality. The verbal part of the meme is sarcastically directed at the Education Minister since it implies that she has no idea how ineffective online classes are. The pictorial part shows in- 
dexically why the mood is sarcastic. The image suggests that students aren't so interested in participating in the lectures. This contrast between the Minister's statement and its exaggerated implementation, as depicted visually, creates a humorous frame.

In this imagetext, we can see a man who covers his head with many masks and wears his glasses over them. He can't see anything, and this exaggeration invites the viewer to ask for an explanation. The verbal part of the meme, "when they tell you that the more times you wear a mask, the sooner the lockdown will end," explains this attitude. The Greek government had proposed that only one mask did not ensure safety and recommended we wear two masks instead. During a crucial period and echoing widespread frustration with pandemic measures, the meme mocks how the government chose to protect people. This meme is grounded on the exaggeration and the unrealistic dimension of the image to create humor.

The last meme titled "how times change..." consists of four frames representing four different decades. Reading from left to right, we see a Greek driver's car accessories in chronological order. A hanging cross acts as a sign of religiousness and a form of protection from car accidents, customary in the '70s. Next, we see various purely decorative accessories from the ' 80 s and '90s. The last frame portrays the protective filtering face mask against Covid-19 that has replaced the previous ones. However, it isn't a decorative accessory but a specialized product to protect us against infection. It has been turned into an element of everyday life, and it has to be accessible at any time. The frame is ironic and stands in contrast to the previous ones because it isn't a car accessory, but a face mask which must not be exposed like (in the harsh environment of the enclosed space of an automobile) this for hygienic purposes.

\section{Conclusions}

In this paper, I have attempted to conduct a meme analysis with a social semiotic perspective (Van Leeuwen 2005; Kress and Van Leeuwen 2006), understanding memes as imagetexts (Mitchell 1994), in combination with humor theory, to detect and explore the discourse of the Covid-19 pandemic in Greek social media (Facebook, Twitter, and Instagram). The comic usually comes from noticing the oddities and absurdities in the world around us. The strange and unusual conditions generated by the pandemic measures have provided fertile ground for many humorous perspectives. Whether taking issue with the common predicament of fear and confinement or public safety rules, internet memes took center stage in expressing public sentiment. At the same time, the whole social media ecosystem became the preferred arena of the politics of the pandemic, from campaigns for public safety and hygiene to conspiracy theories and denialist manifestos. 
The analysis of the memes' meaning indicates deviations from reality or normality and exaggeration as major modes used to create humor. Furthermore, the synergy of semiotic codes enhanced the comic effect (Kostopoulou 2020: 188, 198). The humorous memes studied here showed that the panic had permeated everyday life and influenced the psychology of the Greek people in the first lockdown period: understanding and prudence were the measures taken against the virus. However, during the second lockdown, the memes reflect the people's weariness, psychological fatigue, and frustration at prolonging the government's strict measures.

The public tends to absorb information quickly and shape their stories grounded on critical circumstances like this, primarily when constructed through humor. The primary role of meme humor in social media is to create a vernacular metalanguage, giving people the opportunity to reconsider their attitudes, beliefs, and actions about significant aspects and issues in their lives through an exaggerated perspective.

\section{References}

Aondover, Eric M. 2020. Internet Meme as a Campaign Tool to the Fight against Covid-19 in Nigeria. Global Journal of Human-Social Science Research 20 (6): 27-39.

Barthes, Roland 1977. Image Music Text. London: Fontana Press.

Batič, Janja, and Dragica Haramija 2015. The importance of visual reading for the interpretation of a literary text. CEPS Journal 5 (4): 31-49.

Eco, Umberto 1976. A Theory of Semiotics. Bloomington: Indiana University Press.

Eco, Umberto 1994. Apocalypse postponed. Bloomington: Indiana University Press.

Fairclough, Norman 2003. Analysing Discourse: Textual Analysis for Social Research. London and New York: Routledge.

Fairclough, Norman 2013. Language and Power ( $2^{\text {nd }}$ edition). London and New York: Routledge.

Gamer, Elisabeth-Christine 2013. Configurations of Emptiness: Intericonic Blanks in Louise Lawler's A Movie Without the Picture and Hiroshi Sugimoto's Theaters. In: C. Taban (ed.) Meta-and Inter-Images in Contemporary Visual Art and Culture (115132). Leuven: Leuven University Press.

Grundlingh, Lezandra 2017. Memes as speech acts. Social Semiotics 28 (2): 147-168.

Kostopoulou, Loukia 2020. Humor and intersemiosis in films: Subtitling Asterix and Obelix. Punctum 6 (1): 185-202.

Kress, Gunther, and Theo Van Leeuwen 2006. Reading Images: The Grammar of Visual Design ( $2^{\text {nd }}$ edition). London and New York: Routledge.

Lambert, Frédéric 1986. Mythographies. La photo de presse et ses légendes. Paris: Edilig. 
Mcneill, David, Elena Levy, and Susan Duncan 2015. Gesture in Discourse. In Deborah Tannen, Heidi E. Hamilton, and Deborah Schiffrin (eds.) The Handbook of Discourse Analysis. Oxford: Blackwell.

Mitchell, William John Thomas 1994. Picture Theory: Essays on Verbal and Visual Representation. Chicago: The University of Chicago Press.

Nørgaard, Nina 2009. The Semiotics of Typography in Literary Texts. A Multimodal Approach. Orbis Litterarum 64 (2): 141-160. Malaysia: Blackwell.

Pauliks, Kevin 2020. Memes of the virus: social criticism of the corona pandemic on the internet. TelevIZIon, Jg. 33, Nr. E, S: 46-49.

Schiffrin, Deborah, Deborah Tannen, and Heidi Hamilton 2015. Introduction to the First Edition. In: Deborah Tannen, Heidi Hamilton, and Deborah Schiffrin (eds.) The Handbook of Discourse Analysis. USA \& Oxford: Blackwell Publishers Ltd.

Serafini, Frank and Jennifer Clausen 2012. Typography as a Semiotic Resource. Journal of Visual Literacy 31 (2): 1-16.

Shifman, Limor 2013. Memes in a digital world: Reconciling with a conceptual troublemaker. Journal of Computer-Mediated Communication 18 (3): 362-377.

Shifman, Limor 2014. Memes in digital culture. Cambridge, MA: The MIT Press.

Sipe, Lawrence 1998. How Picture Books Work: Semiotically Framed Theory of TextPicture Relationships. Children's Literature in Education 29 (2): 97-108.

Taecharungroj, Viriya and Pitchanut Nueangjamnong 2015. Humour 2.0: Styles and Types of Humour and Virality of Memes on Facebook. Journal of Creative Communications 10 (3): 288-302.

Van Dijk, Teun 2006. Ideology and discourse analysis. Journal of Political Ideologies 11 (2): 115-140.

Van Leeuwen, Theo 2005. Introducing Social Semiotics. London: Routledge.

\section{AUTHOR}

Thomas Bardakis Ph.D. candidate in Semiotics, School of French Language and Literature, Aristotle University of Thessaloniki, Greece. 